\title{
Distribution and Dispersion of the Troglobitic Carabid Beetle Rhadine subterranea
}

\author{
By Robert W. Mitchell ${ }^{11}$
}

With plates 88 (1)-90 (3)

\section{Introduction}

The purpose of this research was to describe intracave distribution and dispersion patterns within a population of the troglobitic carabid beetle Rhadine subterranea.

Caves and their animals are especially suited to certain kinds of ecological studies because of the considerable isolation of the habitat, the near constancy of the environment, and the relative simplicity of the community structure. These phenomena permit a reasonable hope for progress in the investigation of many biological problems which are exceedingly difficult to approach in the more complex and variable epigeal environments. The dispersion studies to be discussed in this paper illustrate this point quite clearly.

Dispersion patterns within many plant and animal populations have been described in the past, but seldom has an attempt been made to elucidate the causes of the pattern observed. This general sterility of the literature on dispersion has resulted in large part from the many complexly interrelated and highly varying phenomena which operate to cause pattern in epigeal populations. Definable dispersion patterns are certainly structural and functionally adaptable characteristics of populations, and their study should continue to demand the attention of the ecologist, but with greater emphasis upon cause and functional significance of the patterns. Because of the relative simplicity of the cave environment, it was possible in this study not only to describe the dispersion pattern in this beetle population, but also to determine the major factors which produce it and to show that the pattern is of adaptive value.

Rhadine subterranea (Van Dyke) is but one of many troglobitic rhadinid beetles known to inhabit caves of the Edwards Plateau of central Texas. The species has been recorded from several caves near the Balcones Escarp-

1) Department of Biology, Texas Technological College, Lubbock, Texas 79409. 
ment in southern Williamson and northern Travis Counties, Texas (Barr 1960; Barr, Reddell, per. coms.). R. subterranea, described in detail by Barr and Lawrence (1960), is about 7-8 $\mathrm{mm}$ in length, lightly pigmented, and microphthalmous. I have previously shown (1968) that a primary food source of this beetle is the eggs of the cave crickets Ceuthophilus cunicularis and $C$. n. sp. The feeding habits are of great importance in this paper.

The population of $R$. subterranea which I studied inhabits Beck's Ranch Cave (Fig. 1) in southern Williamson Co. (Reddell, 1963). This cave is formed in friable strata of Edwards Limestone of the Lower Cretaceous. There are about $600 \mathrm{~m}$ of accessible passages. The floor lies about $11 \mathrm{~m}$ beneath the surface (at entrance level), and most of its area is covered by a powdery calcareous deposit of varying depth and compactness. For convenience I will refer to this material as silt although it is not an alluvium but rather is formed in place by weathering of the limestone.

\section{Materials and Methods}

Confusion exists in the literature regarding use of the terms "distribution" and "dispersion". In this paper I shall use "distribution" to describe presence or absence and relative abundance of animals in different areas, and "dispersion" to describe pattern; i. e., the nature of the spacing between individuals in areas of occurrence.

Distribution and dispersion data were both obtained by the quadrat count technique. The quadrats were square, $3 \mathrm{dm}$ on a side. Choice of this dimension was dictated by the need to keep the size small to minimize substrate heterogeneity while at the same time being sufficiently large to obtain adequate data.

Quadrats were outlined by wire frames (Fig 2.) constructed of two wires crossed at right angles at their midpoints and soldered. Legs were formed over a template to facilitate bending and to assure uniform frame dimensions. Thus each frame was structurally the two diagonals of a $3 \mathrm{dm}$ square which could be easily visualized when making counts by looking directly down upon the frame or by sighting from leg to leg. The frames were used on silt walls and ceilings by pushing the legs into the substrate, and they could have been used on rocks walls and ceilings as well by tension created by slight inward bending of the legs. These frames, which are easy and inexpensive to make, should be adaptable to making quadrat counts of a great many terrestrial cavernicoles, especially since all substrata save the smoothest rock walls and ceilings should be amenable to sampling by a single method, an important consideration if the data are to be used comparatively. 
The substrate was qualitatively stratified (Table 1), and within each stratum quadrat locations were randomly selected. Locations of the strata are indicated on the detailed map of the Left Tunnel (Fig. 3). A transect line running through each stratum was used as a base for quadrat randomization. This line was randomly placed with respect to the quadrat study since it was laid originally as an aid in mapping. This line was marked at $1 \mathrm{~m}$ intervals, and a mark near a boundary of each stratum was chosen as a reference point. A pair of numbers was obtained from a random numbers table, the first indicating distance along the line from the reference point and the second indicating distance at right angles from the line, left or right depending upon whether this number was even or odd. The distances corresponding to the random numbers were in $1 \mathrm{~m}$ or $1 / 2 \mathrm{~m}$ intervals depending upon the area of a particular stratum. Pairs of numbers were rejected when placement was impossible or when the point indicated was not of the proper stratum. Twenty quadrats were located in each stratum. Ten censuses were made over a 21 day period during the winter (February of 1963) giving 200 quadrat observations in each stratum. There was no regularity in census interval or in time of day when counts were made, although most were made in the afternoon. During the following summer (July of 1964) the quadrat number in Stratum 1 was raised to 64 and three censuses were made.

The quadrat technique was also used to gather data on the dispersion of cave cricket eggs in the silt deposit of Areas 10 and 11. One hundred samples of silt were taken with a Plexiglas device $1 \mathrm{dm}$ on a side which could be pushed into the silt. A sliding bottom which could be inserted after pushing the sampler into the silt permitted the taking of a sample $2 \mathrm{~cm}$ in depth. Sampling sites were randomly selected in the same way as were those for placement of the wire frames used in beetle sampling. Individual silt samples were placed into plastic bags which were then sealed. Each sample was later sieved individually in water through a copper screen of $1 \mathrm{~mm}$ mesh. It was impossible to sieve the silt with this small mesh screen without the use of water. The eggs were easy to see even in the presence of larger particles of limestone because of their shape and smooth surface. Eggs of the two species of cave crickets were easily separable on the basis of size, degree of opacity, and shape. It was not possible for the eggs of either species to pass through the screen.

Data on interaction of the sexes were gathered using experimental chambers (alternative boxes) and methods described elsewhere by me (1968).

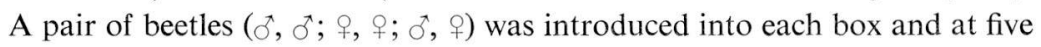
minute intervals for a duration of two hours the beetles were recorded as occurring together (on the same side of the box) or apart. Also recorded was the number of beetle occurrences $(0,1$, or 2$)$ on each box side (designated $\mathrm{X}$ 
and $\mathrm{O}$ respectively). The latter constituted the control data checking for possible bias between $\mathrm{X}$ and $\mathrm{O}$ sides.

\section{Results}

\section{Distribution}

It seemed from qualitative examination of the cave that beetle distribution was localized. Substrata deep, uncompacted silt appeared to have the highest densities while few, if any, beetles were seen on various other types of substrata. The first objective of this research was to examine quantitatively this apparent heterogeneity in distribution.

Table 2 shows the total numbers of beetles ( $f_{o}$ values) recorded from quadrats in each of the nine strata during the February censuses. This observed distribution is compared to an expected distribution ( $f_{e}$ values) which assumes equal density among strata. The large $\chi^{2}$ demonstrates clearly the great heterogeneity in beetle distribution. It is obvious that the greatest contributions to the total $\chi^{2}$ result from the extreme localization of beetles in Strata 1 and 7 . Over $90 \%$ of the beetles observed were present in these strata. These quantitative data merely lend support to a readily observable fact.

\section{Dispersion}

The second objective of this study was to determine the pattern of spacing of individuals in their areas of occurrence; i. e., whether the dispersion was random, contagious, or regular. Only Strata 1 and 7 provided sufficient data for analysis. These data are given in Table 3 in the form of observed frequency distributions of quadrats containing $0,1,--\mathrm{n}$ beetles for the separate census periods.

The most commonly used statistical test for randomness in analyzing such data is the comparison by the $\chi^{2}$ test of an observed frequency distribution with an appropriate Poisson distribution. Often, frequency data pertinent to a specific problem are obtained in component parts (here, from different strata and from several census periods). If there are sufficient data in each component distribution to permit calculation of a $\chi^{2}$ for each, refined analyses based upon the "additive property" of $\chi^{2}$ (Snedecor, 1956) are then possible. This allows calculation of three additional $\chi^{2}$ 's; a summed $\chi^{2}$, the sum of the component $\chi^{2}$ 's; a pooled $\chi^{2}$, a $\chi^{2}$ obtained by pooling component distributions; and a heterogeneity $\chi^{2}$, the difference between summed and pooled $\chi^{2}$ 's. 
Table 4 gives the comparisons of the observed component distributions with their corresponding expected distributions from the Stratum 1 February counts, and Table 5 gives similar comparisons from the Stratum 1 - July data. Table 6 gives the summed, pooled, and heterogeneity $\mathrm{X}^{2}$ 's for all Stratum 1 data. The non-significant $\chi^{2}$ 's in this table permit pooling of the Stratum 1 component distributions. The pooling of the Stratum 7 data is probably permissable although the component distributions could not be tested statistically for heterogeneity. Since this test was impossible, Stratum 7 data were not pooled with Stratum 1 data. Table 7 tests the separate pooled distributions, while Table 8 tests the distribution formed by pooling all Stratum 1 data.

It should be noted that the final expected values in the distributions presented in Tables 4, 5, 7, and 8 have been allowed to fall below five. This is usually not practiced in frequency distribution comparisons because of the possibility of disproportionate contributions to the total $\chi^{2}$ by a small fraction of the data (the least likely events). At the same time it results in loss of information. I allowed the final $f_{e}$ values to fall below five for the following reasons: 1 . The power of the test is increased. 2. The P values obtained are conservative. 3. It is essential to have at least three classes in each distribution. Otherwise, there would be no d. f. available for a twoclass distribution making it impossible to apply the $\chi^{2}$ test.

Other tests for departure from randomness are available. One is the variance $\left(\mathrm{s}^{2}\right)$ : mean $(\mathrm{m})$ ratio rest. This test is often used when the mean is low (in the range of the means from the beetle data) since low means will often result in a two-class distribution with no $d$. $f$. Depending upon the nature of the observed frequency values, either the $\chi^{2}$ test or the $\mathrm{s}^{2}: \mathrm{m}$ ratio test may detect departure from randomness while the other fails to do so (GreigSmith, 1964). So, apart from the occasional necessity to use a test other than $\chi^{2}$, the $\mathrm{s}^{2}: \mathrm{m}$ ratio test may prove valuable.

The test is based upon the fact that in a Poisson distribution the $\mathrm{m}=\mathrm{s}^{2}$. If $\mathrm{s}^{2}: \mathrm{m}$ in the observed distribution is $>1$, contagion is indicated; if $<1$, regularity is indicated. Significance of the difference between the observed ratio and unity may be tested with the $t$ test (Greig-Smith, 1964). Application of the $\mathrm{s}^{2}: \mathrm{m}$ test to the Stratum $1-$ February data yields $\mathrm{s}^{2}: \mathrm{m}=1.0765$, $t=.7627 / 199$ d. f., and $\mathrm{P}>.40$. Stratum $1-$ July data yield $\mathrm{s}^{2}: \mathrm{m}=.8732$, $t=1.2395 / 191 \mathrm{~d}$. f., and $\mathrm{P}>.20$. Stratum 7 data yield $\mathrm{s}^{2}: \mathrm{m}=1.0796$, $t=.7926 / 199 \mathrm{~d} . \mathrm{f}$., and $\mathrm{P}>.40$. In testing the distribution formed by pooling all Stratum 1 data, $\mathrm{s}^{2}: \mathrm{m}=1.0368, t=.5147 / 391 \mathrm{~d}$. f., and $\mathrm{P}>.60$. It is obvious that in no instance does the $\mathrm{s}^{2}: \mathrm{m}$ test indicate significant departure from random expectation.

Less powerful tests for randomness based upon numbers of occupied and unoccupied quadrats are given by Greig-Smith (1964). These tests make use 
of the fact that in a contagiously dispersed population there will be more unoccupied quadrats than in a random dispersion of the same density. Conversely, there will be fewer unoccupied quadrats in a regularly dispersed population than a random one of equal density. It is obvious that these tests would fail to indicate departure from randomness since the $f_{o}$ and $f_{e}$ values (Tables 7 and 8 ) for class 0 are nearly equal.

In addition to the foregoing beetle dispersion data, limited data were also obtained on the dispersion of cave cricket eggs in the deep silt substrate of Areas 10 and 11. Table 9 shows the comparisons of observed frequency distributions of these eggs with appropriate Poisson distributions. Not only does the distribution of eggs without regard to species fail to depart significantly from expectation, but neither do the separate distributions for the two species of crickets. It may be assumed that cricket egg dispersion in the homogeneous silt deposit of Areas 10 and 11 is random.

The 100 samples comprised one $\mathrm{m}^{2}$ of substrate, and yielded a total of 50 eggs. Treating the number of eggs as a Poisson variable (Ricker, 1948) gives an estimate, with $95 \%$ confidence limits, of 37 to 66 eggs per $\mathrm{m}^{2}$ of substrate surface at the time of sampling, late November of 1964.

Frequency distributions compiled from the sex interaction experiments were compared with appropriate $1: 1$ expected distributions giving the following results.

$0^{\star}$, o Control: $1156 \mathrm{X}, 1148 \mathrm{O}, \mathrm{X}^{2}=.028, \mathrm{P}>.80$.

우 우 Control: $1158 \mathrm{X}, 1146 \mathrm{O}, \mathrm{X}^{2}=.062, \mathrm{P}>.80$.

$0^{\circ}$, o Control: $1154 \mathrm{X}, 1150 \mathrm{O}, \mathrm{X}^{2}=.006, \mathrm{P}>.90$.

ơ, ot Experimental: $464 \mathrm{~T}$ (occurrences of both beetles on same box side), 688 A (occurrences of beetles on different box sides), $\chi^{2}=43.56, \mathrm{P}<.001$. Males preferred to remain apart.

ㅇ, 아 Experimental: $494 \mathrm{~T}, 658 \mathrm{~A}, \mathrm{X}^{2}=23.35, \mathrm{P}<.001$. Females preferred to remain apart.

ơ, ㅇ Experimental: $615 \mathrm{~T}, 537 \mathrm{~A}, \mathrm{X}^{2}=5.28, \mathrm{P}<.02$. Males and females preferred to remain together. An additional experiment was run after a lapse of 24 hours during which time the beetles were left together in the boxes. This yielded $639 \mathrm{~T}, 513 \mathrm{~A}, \mathrm{X}^{2}=13.78, \mathrm{P}<.001$. Males and females still preferred to remain together. This experiment also provided some incidental information about mating. During the initial two-hour period 17 of 48 pairs mated, and during the latter period 11 pairs mated. If a pair of beetles will mate without respect to previous matings, then 17/48's of the number mating during the second period should have mated during the first period also. 17/48's of $11=3.9$. Three pairs of beetles mated during both periods.

To determine if there was a significant difference between degree of $0^{\star}, 0^{\star}$ and $q, q$ experimental distributions were compared with each other in a 
$2 \times 2$ contingency table. This test yielded a $\chi^{2}=1.50$ and a $P>.20$ indicating no significant difference in intrasex repulsion between the two sexes.

Since in a population of animals in which there is a $1: 1$ sex ratio (numerous checks on $R$. subterranea sex ratio indicated no significant departure from $1: 1$ ), there exists also a $1: 1$ ratio in potential intersex vs. intrasex pairings. Because of this it is possible to compare the preceeding data in such a way to obtain an indication of any difference between intrasex repulsion and intersex attraction. A $2 \times 2$ contingency table constructed as follows may be used in this test. An event is either an occurrence of the beetles together or apart.

\begin{tabular}{|c|c|c|c|}
\hline & $\begin{array}{l}\text { More common } \\
\text { event }\end{array}$ & $\begin{array}{l}\text { Less common } \\
\text { event }\end{array}$ & \\
\hline$\sigma^{\lambda}, \sigma^{\star}$ and $+q$ events & $1346(\mathrm{~A})$ & $958(\mathrm{~T})$ & 2304 \\
\hline \multirow[t]{2}{*}{$o, q$ events } & $615(\mathrm{~T})$ & $537(\mathrm{~A})$ & 1152 \\
\hline & 1961 & 1495 & 3456 \\
\hline
\end{tabular}

This table yields an $\chi^{2}=7.73$ and a $\mathrm{P}<.01$ indicating significant departure from homogeneity in the distributions compared. It is thus apparent that the relative strengths of intersex attraction and intrasex repulsion are not equally counterbalancing, but that the strength of intrasex repulsion exceeds that of intersex attraction (under the experimental conditions imposed).

\section{Discussion}

Intracave distribution was so markedly heterogeneous that the quadrat study failed to reveal any gross distributional phenomena not readily apparent from observation. Not only were beetle densities the highest in those areas of deep, uncompacted silt, but beetles were almost entirely restricted to these areas. Beetle larvae were found in this silt, so it is possible that reproduction has some role in this distribution, but the primary reason probably is that these areas are the most favorable sites for cave cricket oviposition.

Although the presence of cricket eggs in this silt has been demonstrated (Table 9 and Results), presumptive evidence must suffice in lieu of detailed studies of the cave crickets themselves that oviposition is concentrated here. When a female cricket oviposits, the full length of the ovipositor (slightly $>1 \mathrm{~cm}$ in $C$. cunicularis and slightly $<1 \mathrm{~cm}$ in $C$. $\mathrm{n}$. sp.) is inserted into the substrate. Obviously, oviposition cannot occur in rock, nor does a thin covering of silt over a rocky substrate seem any more favorable. The deep, 
but compacted, silt deposits do not appear to be suitable either. Although the ovipositor is one of the most highly sclerotized structures of a cave cricket, it is not rigid and inflexible. It can possibly be pushed into a soft substrate only, although it must be remembered that many insects insert their delicate ovipositors into a very hard substrate. An ovipositing cricket lifts her abdomen high and flexes it until the ovipositor is approximately at right angles to the substrate. She then probes about the surface of the substrate with the tip of the ovipositor for a time before inserting it, giving every appearance of a search for the softest location. These observations suggest that the deep, uncompacted silt is the substrate preferred for oviposition.

The most interesting data to come from the quadrat study are those relating to dispersion. Since none of the $\chi^{2}$ 's in Tables $4-8$ are significant, there is no reason to refute the null hypothesis that the observed frequencies are merely chance departures from Poisson expectation. Random dispersions have seldom been discovered in natural populations of either plants or animals (Greig-Smith, 1964; Andrewartha and Birch, 1954; Cole, 1946). Departures from randomness are almost always in the direction of contagion rather than regularity. So common is contagion that it has prompted the development of a body of mathematical analyses which attempt its description (Greig-Smith, 1964). No comparable theory has developed about the regular dispersion.

In a truly random dispersion the occurrence of an event $(1,2,--n$ individuals per sampling unit) is due to chance alone; i. e., presence or absence of an individual in no way influences presence or absence of other individuals. Because of the active and passive interactions between living individuals, it is apparent why random dispersions are seldom encountered in natural populations. However, when randomness is indicated by a statistical test, it does not necessarily follow that these living individuals are not in some way acting upon each other. It seems to have been generally overlooked that a "random" dispersion in nature may be an emergent effect of interactions just as are the more obvious contagious and regular dispersions. The failure of an observed frequency distribution to depart significantly from an appropriate expected random distribution may not necessarily, then, be an indication of "statistical randomness".

The dispersion data of $R$. subterranea illustrate the preceeding clearly. Although none of the observed frequency distributions differed significantly from random expectation, it cannot be assumed that individual beetles were not interacting. Quite to the contrary, the interaction experiments demonstrated very definite interactions, individuals of the same sex tending to repel each other and individuals of the opposite sex tending to attract each other. I have no experimental data relating to the means whereby one beetly detects 
another in the absence of physical contact. However, the beetles do produce a distinct pungent odor, and I suspect that chemoreception is an important, if not the primary, mechanism operative here. I have seen male beetles proceed to females in a direct line from distances of at least one $\mathrm{dm}$, so it is apparent that detection without physical contact does occur.

Intersex attraction is of obvious selective advantage. The two of, o interaction experiments show that attraction between the sexes persists through time even though matings may occur. This is an important finding since it indicates that intersex attraction is a continuing force influencing the dispersion pattern.

The selective advantage of intrasex repulsion is probably associated with the beetles, use of cave cricket eggs as food and the dispersion of these eggs. Since female cave crickets deposit eggs singly, moving to a new location after each ovipostion, it would seem that egg dispersion would at least not be highly contagious. Table 9 shows that cricket egg dispersion was, in fact, random within an area of homogeneous silt substrate (precisely that area where the beetle dispersion data were gathered).

Since one egg will suffice to engorge only a single beetle and since the eggs are not contagiously dispersed, it follows that contagion in beetle dispersion would not be at a selective advantage. Rather, selection for the greatest efficiency in food location and utilization would result in a beetle dispersion tending toward regularity. In fact, if reproduction could be dismissed, I would fully expect the beetle dispersion to be regular, but regularity is broken up by intersex attraction.

Although none of the observed dispersion patterns departed significantly from random expectation, the goodness of fit was, of course, never perfect. I believe that it is instructive to examine the direction of departure from expectation which is best revealed in the Stratum 1 pooled distribution (Table 8). There were fewer quadrats with no beetles than expected, more with one beetle than expected, and less with two beetles than expected. While none of these shows drastic departure from its corresponding $f_{e}$ value, each is exactly the kind of difference to be expected in a dispersion tending toward regularity. Since there are several other combinations of ways in which the $f_{o}$ values might have departed from expectation, there is at least the suggestion that the kinds of $f_{o}-f_{e}$ differences in Table 8 are not coincidental. This direction of departure would also seem to be an anticipated result since the interaction experiments suggest a greater strength of intrasex repulsion than of intersex attraction. But, again, it must be stressed that the differences between observed and expected values were not great enough to indicate significant departure from random expectation. In fact, if the $f_{o}$ values in Table 8 are truly proportionate, it would require their doubling before a significant departure from randomness could be demonstrated. 
The quadrat data and the sex interaction data gathered in this study seem sufficient to describe the major features associated with dispersion in this population of Rhadine subterranea. Intersex attraction tends to produce contagion while intrasex attraction tends to produce regularity. These opposing forces create a dispersion pattern which does not depart significantly from randomness, although there is a departure toward regularity resulting from the greater strenght of intrasex repulsion. The emergent pattern is of adaptive value since it results in efficient utilization of a primary food source while at the same time providing opportunity for mating.

novembre 1967 
Table 1

Locations and descriptions of strata sampled in quadrat study.Locations refer to areas indicated in Fig. 3.

\begin{tabular}{ccl} 
Stratum & Location & \multicolumn{1}{c}{ Description } \\
\hline 1 & Area 10 & $\begin{array}{l}\text { Deep, uncompacted silt on floor. Depth }>1 \mathrm{~cm}, \\
\text { usually much greater; in some places up to } 1 / 2 \mathrm{~m} . \\
\text { Very few rocks present. }\end{array}$ \\
\hline 2 & Area 12 & $\begin{array}{l}\text { Deep, compacted silt on floor, chiefly covering large } \\
\text { breakdown boulders. Depth }>1 \mathrm{~cm}, \text { but seldom } \\
>1 \mathrm{dm} .\end{array}$
\end{tabular}

\begin{tabular}{cll}
\hline 3 & Area 11 & Deep, compacted silt on wall. Depth $>1 \mathrm{~cm}$. \\
\hline 4 & Area 7 & $\begin{array}{l}\text { Wet rock. Film of water covering travertine. Water } \\
\text { was dripping from ceiling and overflowing from drip } \\
\text { pools. }\end{array}$ \\
\hline
\end{tabular}

5 Area 5 Wet silt with high organic content evidenced by very dark coloration. Moisture maintained by overflow from pools behind small travertine dams. Depth $<1 \mathrm{~cm}$ in most places.

\begin{tabular}{lll}
\hline 6 & $\begin{array}{l}\text { Areas 1, } \\
\text { 8, and } 10\end{array}$ & $\begin{array}{l}\text { Dry rock with no silt cover. "Dry" indicates only } \\
\text { that no obvious film of water was present; all cave } \\
\text { surfaces were more or less moist. }\end{array}$ \\
\hline 7 & Area 3 & $\begin{array}{l}\text { Deep, uncompacted silt on floor. Similar to Stratum } \\
\text { 1, but depth less; }>1 \mathrm{~cm} \text { but }<1 \mathrm{dm} \text {. Numerous } \\
\text { small rocks present. }\end{array}$ \\
\hline 8 & Area 12 & $\begin{array}{l}\text { Deep, compacted silt on ceiling. Depth generally } \\
1 \mathrm{dm} .\end{array}$ \\
\hline 9 & Area 6 & $\begin{array}{l}\text { Thin, compact silt on floor, chiefly covering large } \\
\text { breakdown boulders. Simlilar to Stratum } 2 \text { except } \\
\text { that depth of silt }<1 \mathrm{~cm} .\end{array}$
\end{tabular}

Table 2

Test for heterogeneity in beetle density between strata. The $f_{o}$ values are numbers of beetles recorded in 200 quadrat observations in each stratum. The $\mathrm{f}_{\mathrm{e}}$ values are numbers expected assuming equal density among strata.

\begin{tabular}{rrrr} 
Stratum & $\mathrm{f}_{\mathrm{o}}$ & \multicolumn{1}{c}{$\mathrm{f}_{\mathrm{e}}$} & \multicolumn{1}{c}{$\chi^{2}$} \\
\hline 1 & 108 & 18.56 & 431.01 \\
2 & 4 & 18.56 & 11.42 \\
3 & 4 & 18.56 & 11.42 \\
4 & 0 & 18.56 & 18.56
\end{tabular}




\begin{tabular}{rrcc} 
Stratum & $\mathrm{f}_{\mathrm{o}}$ & $\mathrm{f}_{\mathrm{e}}$ & $\chi^{2}$ \\
\hline 5 & 1 & 18.56 & 16.61 \\
6 & 0 & 18.56 & 18.56 \\
7 & 46 & 18.56 & 40.57 \\
8 & 0 & 18.56 & 18.56 \\
9 & 4 & 18.56 & 11.41
\end{tabular}

$\chi^{2} / 8$ d. f. $=578.13$

$\stackrel{\mathrm{P}}{2}<.001$

Table 3 .

Observed frequencies of quadrats containing $0,1,2,3$, or 4 beetles for the separate census periods. Class $=$ number of beetles per quadrat.

Stratum 1 - February

Census Period

\begin{tabular}{rrrrrrrrrrrr} 
Class & 1 & 2 & 3 & 4 & 5 & 6 & 7 & 8 & 9 & 10 & $\Sigma \mathrm{f}_{\mathrm{o}}$ \\
\hline 0 & 9 & 7 & 11 & 13 & 12 & 13 & 13 & 11 & 14 & 12 & 115 \\
1 & 8 & 11 & 8 & 5 & 8 & 5 & 5 & 9 & 5 & 5 & 69 \\
2 & 3 & 1 & 1 & 2 & 0 & 2 & 1 & 0 & 0 & 2 & 12 \\
3 & 0 & 0 & 0 & 0 & 0 & 0 & 0 & 0 & 1 & 0 & 1 \\
4 & 0 & 1 & 0 & 0 & 0 & 0 & 1 & 0 & 0 & 1 & 3
\end{tabular}

Stratum 1 - July

Census Period

\begin{tabular}{crrrr} 
Class & 1 & 2 & 3 & $\Sigma f_{0}$ \\
\hline 0 & 43 & 48 & 48 & 139 \\
1 & 19 & 14 & 15 & 48 \\
2 & 2 & 2 & 1 & 5
\end{tabular}

Stratum 7 - February

Census Period

\begin{tabular}{crrrrrrrrrrr} 
Class & 1 & 2 & 3 & 4 & 5 & 6 & 7 & 8 & 9 & 10 & $\Sigma \mathrm{f}_{\mathrm{o}}$ \\
\hline 0 & 13 & 15 & 12 & 16 & 15 & 15 & 18 & 18 & 20 & 17 & 159 \\
1 & 6 & 5 & 8 & 3 & 5 & 4 & 2 & 2 & 0 & 3 & 38 \\
2 & 0 & 0 & 0 & 0 & 0 & 1 & 0 & 0 & 0 & 0 & 1 \\
3 & 1 & 0 & 0 & 1 & 0 & 0 & 0 & 0 & 0 & 0 & 2
\end{tabular}


Table 4.

Stratum 1 - February data. Comparisons of the observed component distributions with their corresponding expected distributions. $\mathrm{f}_{\mathrm{o}}=$ number of quadrats observed to contain that number of beetles indicated by class value. $\mathrm{f}_{\mathrm{e}}=$ number of quadrats expected to contain $0,1,--n$ beetles as calculated from Poisson probability distribution. $\mathrm{N}=$ total number of quadrats. $\mathrm{B}=$ total number of beetles. $\mathrm{m}=$ mean number of beetles per quadrat. $\mathrm{e}=$ base of natural logarithms.

Census 1

\begin{tabular}{|c|c|c|c|c|}
\hline Class & $f_{o}$ & $\mathrm{f}_{\mathrm{e}}$ & $\chi^{2}$ & \\
\hline 0 & 9 & 9.93 & .087 & $\mathrm{~N}=20, \mathrm{~B}=14, \mathrm{~m}=.70$ \\
\hline 1 & 8 & 6.95 & .159 & $\mathrm{e}-\mathrm{m}=.496585$ \\
\hline 2 & 3 & 3.12 & .005 & $\begin{array}{l}\chi^{2} / 1 \text { d. f. }=.251 \\
\mathrm{P}>.50\end{array}$ \\
\hline
\end{tabular}

Census 2

\begin{tabular}{lrrr} 
Class & $\mathrm{f}_{\mathrm{o}}$ & $\mathrm{f}_{\mathrm{e}}$ & \multicolumn{1}{c}{$\chi^{2}$} \\
\hline 0 & 7 & 8.56 & .284 \\
1 & 11 & 7.28 & 1.901 \\
$2+$ & 2 & 4.16 & 1.122
\end{tabular}

$\mathrm{N}=20, \mathrm{~B}=17, \mathrm{~m}=.85$

$\mathrm{e}-\mathrm{m}=.427415$

$\chi^{2} / 1$ d. f. $=3.307$

$\mathrm{P}>.05$

Census 3

\begin{tabular}{lrrr} 
Class & $\mathrm{f}_{\mathrm{o}}$ & \multicolumn{1}{c}{$\mathrm{f}_{\mathrm{e}}$} & $\chi^{2}$ \\
\hline 0 & 11 & 12.13 & .087 \\
1 & 8 & 6.07 & .614 \\
2 & 1 & 1.80 & .356
\end{tabular}

$\mathrm{N}=20, \mathrm{~B}=10, \mathrm{~m}=.50$

$\mathrm{e}^{-\mathrm{m}}=.606531$

$\chi^{2} / 1$ d. f. $=1.057$

$\stackrel{\mathrm{P}}{\chi}=.30$

Census 4

\begin{tabular}{lrrll} 
Class & $\mathrm{f}_{\mathrm{o}}$ & \multicolumn{1}{c}{$\mathrm{f}_{\mathrm{e}}$} & \multicolumn{1}{c}{$\chi^{2}$} & \\
\cline { 1 - 1 } & 13 & 12.75 & .005 & $\mathrm{~N}=20, \mathrm{~B}=9, \mathrm{~m}=.45$ \\
1 & 5 & 5.74 & .095 & $\mathrm{e}-\mathrm{m}=.637628$ \\
2 & 2 & 1.51 & .159 & $\chi^{2} / 1 \mathrm{~d} . \mathrm{f} .=.259$ \\
& & & & $\mathrm{P}>.50$
\end{tabular}

Census 5

\begin{tabular}{lrrr} 
Class & \multicolumn{1}{c}{$\mathrm{f}_{\mathrm{o}}$} & \multicolumn{1}{c}{$\mathrm{f}_{\mathrm{e}}$} & \multicolumn{1}{c}{$\chi^{2}$} \\
\hline 0 & 12 & 13.41 & .148 \\
1 & 8 & 5.36 & 1.300 \\
2 & 0 & 1.23 & 1.230
\end{tabular}

$\mathrm{N}=20, \mathrm{~B}=8, \mathrm{~m}=.40$

$\mathrm{e}-\mathrm{m}=.670320$

$\chi^{2} / 1$ d. f. $=2.678$

$\stackrel{\mathrm{P}}{\chi}>.10$ 
Census 6

\begin{tabular}{lrrll} 
Class & $\mathrm{f}_{\mathrm{o}}$ & \multicolumn{1}{c}{$\mathrm{f}_{\mathrm{e}}$} & $\chi^{2}$ & \\
\hline 0 & 13 & 12.75 & .005 & $\mathrm{~N}=20, \mathrm{~B}=9, \mathrm{~m}=.45$ \\
1 & 5 & 5.74 & .095 & $\mathrm{e}-\mathrm{m}=.637628$ \\
2 & 2 & 1.23 & .159 & $\begin{array}{l}\chi^{2} / 1 \text { d. } \mathrm{f}=.259 \\
\end{array}$ \\
& & & & $\mathrm{P}>.50$
\end{tabular}

Census 7

\begin{tabular}{lrrr} 
Class & \multicolumn{1}{c}{$\mathrm{f}_{\mathrm{o}}$} & \multicolumn{1}{c}{$\mathrm{f}_{\mathrm{e}}$} & $\chi^{2}$ \\
\hline 0 & 13 & 11.54 & .185 \\
1 & 5 & 6.35 & .287 \\
$2+$ & 2 & 2.11 & .006
\end{tabular}

$\mathrm{N}=20, \mathrm{~B}=11, \mathrm{~m}=.55$

$\mathrm{e}-\mathrm{m}=.576950$

$\chi^{2} / 1$ d. f. $=.478$

$\stackrel{\mathrm{P}}{\chi}>.30$

Census 8

\begin{tabular}{lrrr} 
Class & $\mathrm{f}_{\mathrm{o}}$ & \multicolumn{1}{c}{$\mathrm{f}_{\mathrm{e}}$} & \multicolumn{1}{c}{$\chi^{2}$} \\
\hline 0 & 11 & 12.75 & .240 \\
1 & 9 & 5.74 & 1.851 \\
2 & 0 & 1.51 & 1.510
\end{tabular}

$\mathrm{N}=20, \mathrm{~B}=9, \mathrm{~m}=.45$

$\mathrm{e}-\mathrm{m}=.637628$

$\chi^{2} / 1$ d. f. $=3.601$

$\stackrel{\mathrm{P}}{\chi}>.05$

Census 9

\begin{tabular}{lrrll} 
Class & $\mathrm{f}_{\mathrm{o}}$ & \multicolumn{1}{c}{$\mathrm{f}_{\mathrm{e}}$} & \multicolumn{1}{c}{$\chi^{2}$} & \\
\hline 0 & 14 & 13.41 & .026 & $\mathrm{~N}=20, \mathrm{~B}=8, \mathrm{~m}=.40$ \\
1 & 5 & 5.36 & .024 & \\
$2+$ & 1 & 1.23 & .043 &
\end{tabular}

Census 10

\begin{tabular}{lrrll} 
Class & $\mathrm{f}_{\mathrm{o}}$ & \multicolumn{1}{c}{$\mathrm{f}_{\mathrm{e}}$} & \multicolumn{1}{c}{$\chi^{2}$} & \\
\cline { 1 - 3 } 0 & 12 & 10.44 & .243 &
\end{tabular}




\section{Table 5}

Stratum 1 - July data. Comparisons of the observed component distributions with their corresponding expected distributions. Symbols as in Table 4.

\section{Census 1}

\begin{tabular}{lrrr} 
Class & $\mathrm{f}_{\mathrm{o}}$ & $\mathrm{f}_{\mathrm{e}}$ & $\chi^{2}$ \\
\hline 0 & 43 & 44.65 & .061 \\
1 & 19 & 16.07 & .534 \\
2 & 2 & 3.28 & .500
\end{tabular}

$$
\begin{aligned}
& \mathrm{N}=64, \mathrm{~B}=23, \mathrm{~m}=.36 \\
& \mathrm{e}^{-\mathrm{m}=.697676}
\end{aligned}
$$$$
\chi^{2} / 1 \text { d. f. }=1.095
$$

$\stackrel{\mathrm{P}}{>} .25$

\section{Census 2}

\begin{tabular}{lrrr} 
Class & $\mathrm{f}_{\mathrm{o}}$ & $\mathrm{f}_{\mathrm{e}}$ & $\chi^{2}$ \\
\hline 0 & 48 & 48.37 & .003 \\
1 & 14 & 13.54 & .016 \\
2 & 2 & 2.09 & .004
\end{tabular}

$\mathrm{N}=64, \mathrm{~B}=18, \mathrm{~m}=.28$

$\mathrm{e}^{-\mathrm{m}}=.755784$

$\chi^{2} / 1$ d. f. $=.023$

$\mathrm{P}>.80$

\section{Census 3}

\begin{tabular}{lrrll} 
Class & $\mathrm{f}_{\mathrm{o}}$ & $\mathrm{f}_{\mathrm{e}}$ & $\chi^{2}$ & \\
\hline 0 & 48 & 48.85 & .015 & $\mathrm{~N}=64, \mathrm{~B}=17, \mathrm{~m}=.27$ \\
1 & 15 & 13.19 & .248 & $\mathrm{e}-\mathrm{m}=.763379$ \\
2 & 1 & 1.96 & .470 & $\chi^{2} / 1$ d. f. $=.733$ \\
& & & & $\mathrm{P}>.30$
\end{tabular}

Table 6

Summed, pooled, and heterogeneity $\chi^{2}$ 's for the Stratum 1 data.

Stratum 1 - February

\begin{tabular}{lcrc} 
& d. f. & \multicolumn{1}{c}{$\chi^{2}$} & $\mathrm{P}$ \\
\hline Summed $\chi^{2}$ & 10 & 12.717 & $>.20$ \\
Pooled $\chi^{2}$ & 2 & 2.135 & $>.30$ \\
Heterogeneity $\chi^{2}$ & 8 & 10.582 & $>.20$
\end{tabular}

Stratum $1-$ July

\begin{tabular}{lccc} 
& d.f. & $\chi^{2}$ & P \\
\hline Summed $\chi^{2}$ & 3 & 1.851 & $>.70$ \\
Pooled $\chi^{2}$ & 1 & 1.615 & $>.20$ \\
Heterogeneity $\chi^{2}$ & 2 & .236 & $>.80$
\end{tabular}




\begin{tabular}{lcrc}
\multicolumn{4}{c}{ Stratum 1 } \\
& d.f. & $\chi^{2}$ & Pooled Data \\
\hline Summed $\chi^{2}$ & 13 & 14.568 & $>.30$ \\
Pooled $\chi^{2}$ & 2 & 2.268 & $>.30$ \\
Heterogeneity $\chi^{2}$ & 11 & 11.300 & $>.30$
\end{tabular}

Table 7

Comparisons of the separate pooled distributions with their corresponding expected distributions.

Stratum $1-$ February

\begin{tabular}{lrrrl} 
Class & \multicolumn{1}{c}{$\mathrm{f}_{\mathrm{o}}$} & \multicolumn{1}{c}{$\mathrm{f}_{\mathrm{e}}$} & \multicolumn{1}{c}{$\chi^{2}$} & \\
\cline { 1 - 3 } & 115 & 116.55 & .021 & $\mathrm{~N}=200, \mathrm{~B}=108, \mathrm{~m}=.54$ \\
1 & 69 & 62.94 & .583 & $\mathrm{e}-\mathrm{m}=.582748$ \\
2 & 12 & 16.99 & 1.466 & $\chi^{2} / 2$ d. f. $=2.135$ \\
$3+$ & 4 & 3.52 & .065 &
\end{tabular}

Stratum 1 - July

\begin{tabular}{|c|c|c|c|c|}
\hline Class & $f_{o}$ & $f_{e}$ & $\chi^{2}$ & \\
\hline 0 & 139 & 142.24 & .074 & $\mathrm{~N}=192, \mathrm{~B}=58, \mathrm{~m}=.30$ \\
\hline 1 & 48 & 42.67 & .667 & $\mathrm{e}^{-\mathrm{m}}=.740818$ \\
\hline 2 & 5 & 7.09 & .874 & $\begin{array}{l}\chi^{2} / 1 \text { d. f. }=1.615 \\
\mathbf{P} \geq .20\end{array}$ \\
\hline
\end{tabular}

Stratum 7 - February

\begin{tabular}{lrrll} 
Class & \multicolumn{1}{c}{$\mathrm{f}_{\mathrm{o}}$} & \multicolumn{1}{c}{$\mathrm{f}_{\mathrm{e}}$} & $\chi^{2}$ & \\
\hline 0 & 159 & 158.91 & .000 & $\mathrm{~N}=200, \mathrm{~B}=46, \mathrm{~m}=.23$ \\
1 & 38 & 36.55 & .058 & \\
$2+$ & 3 & 4.54 & .522 & $\mathrm{e}^{-\mathrm{m}}=.794534$ \\
& & & & $\mathrm{P}>\mathrm{d} . \mathrm{f}=.580$
\end{tabular}

Table 8

Comparison of the Stratum 1 pooled distribution with its corresponding expected distribution.

\begin{tabular}{lrrrl} 
Class & \multicolumn{1}{c}{$\mathrm{f}_{\mathrm{o}}$} & \multicolumn{1}{c}{$\mathrm{f}_{\mathrm{e}}$} & \multicolumn{1}{c}{$\chi^{2}$} & \\
\hline 0 & 254 & 257.56 & .049 & $\mathrm{~N}=392, \mathrm{~B}=166, \mathrm{~m}=.42$ \\
1 & 117 & 108.18 & .719 & $\mathrm{e}-\mathrm{m}=.657047$ \\
2 & 17 & 22.72 & 1.440 & $\chi^{2} / 2$ d. f. $=2.268$ \\
$3+$ & 4 & 3.54 & .060 & $\mathrm{P}>.30$
\end{tabular}




\section{Table 9}

Comparisons of observed frequency distributions of cave cricket eggs in the silt of Areas 10 and 11 with their corresponding expected distributions.

\section{Ceuthophilus cunicularis}

\begin{tabular}{|c|c|c|c|c|}
\hline & $f_{o}$ & $f_{e}$ & $\chi^{2}$ & \\
\hline 0 & 80 & 78.66 & .023 & $\mathrm{~N}=100$, no. eggs $=24, \mathrm{~m}=.24$ \\
\hline 1 & 17 & 18.88 & .187 & $\mathrm{e}^{-\mathrm{m}}=.786628$ \\
\hline $2+$ & 3 & 2.46 & .119 & $\chi^{2} / 1$ d. f. $=.329, \mathrm{P}>.50$ \\
\hline
\end{tabular}

Ceuthophilus n. sp.

\begin{tabular}{rrrll} 
& $\mathrm{f}_{\mathrm{o}}$ & \multicolumn{1}{c}{$\mathrm{f}_{\mathrm{e}}$} & \multicolumn{1}{c}{$\chi^{2}$} & \\
\cline { 1 - 2 } 0 & 78 & 77.10 & .011 &
\end{tabular}

Both species

\begin{tabular}{|c|c|c|c|c|}
\hline & $f_{o}$ & $\mathrm{f}_{\mathrm{e}}$ & $\chi^{2}$ & \\
\hline 0 & 63 & 60.65 & .091 & $\mathrm{~N}=100$, no. eggs $=50, \mathrm{~m}=.50$ \\
\hline 1 & 27 & 30.32 & .363 & $\mathrm{e}^{-\mathrm{m}}=.606531$ \\
\hline 2 & 7 & 7.58 & .044 & $\chi^{2} / 2$ d. f. $=2.155, \mathrm{P}>.30$ \\
\hline $3+$ & 3 & 1.45 & 1.657 & \\
\hline
\end{tabular}

\section{EXPLANATIONS OF PLATES 88 (1) - 90 (3)}

Plate 88 (1): Beck's Ranch Cave, outline of accessible portion Plate 89 (2): Design of wire frame for outlining quadrat.

Plate 90 (3): Left Tunnel of Beck's Ranch Cave, detail of substrate.

\section{ACKNOWLEDGEMENTS}

I wish to thank Mr. E. O. Beck for his full cooperation with me during my studies in the caves located on his ranch. I also extend appreciation to Dr. Bassett Maguire, Jr., Dr. H. Grey Merriam, Dr. Bert A. Tribbey, Mr. James R. Reddell, and Dr. Bobbi Lowe. Mr. William Russell provided the outline map in Fig. 1. I thank all members of the University of Texas Speleological Society for assisting in leaving Beck's Ranch Cave undisturbed during my studies.

\section{SUMMARY}

Intracave distribution and dispersion patterns within a population of the troglobitic carabid beetle Rhadine subterranea were studied. Distribution was markedly heterogeneous, the beetles being almost entirely restricted to substrata of deep, uncompacted silt. Dispersion of the beetles on the silt substrata did not depart from random expectation. It is shown, however, that this is a functionally emergent pattern resulting from an intrasex repulsion related to feeding which tends to produce regularity counterbalanced by an intersex attraction related to reproduction which tends to produce contagion. 


\section{RESUME}

L'étude de la distribution et du type (pattern) de dispersion du Carabique troglobie Rhadine subterranea a été effectuée sur une population de cet Insecte.

La distribution est nettement hétérogène, les Insectes étant presque tous inféodés à un sol particulier, profond et non compact, analogue à un limon. Leur dispersion sur ce substrat ne diffère pas d'une distribution supposée due au hasard. On a pu cependant démontrer que le type particulier de distribution découvert est dû à l'équilibre qui s'établit entre la répulsion des individus du même sexe (ce qui tend à produire la régularité de la distribution) et l'attraction entre individus de sexes opposés (ce qui tend à provoquer des rassemblements).

\section{REFERENCES CITED}

Andrewartha, H. G., and L. C. Birch (1954) - The distribution and abundance of animals. Chicago, Univ. of Chicago Press. $782 \mathrm{pp}$.

BARR, T. C. (1960) - The cavernicolous beetles of the subgenus Rhadine, genus Agonum (Coleoptera: Carabidae). Am. Midl. Nat., 64 (1): 45-65.

-, and J. F. LaWrence. (1960) - New cavernicolous Agonum (Rhadine) from Texas (Coleoptera: Carabidae). Wasmann J. Biol., 18 (1): 137-145.

Cole, L. C. (1946) - A study of the cryptozoa of an Illinois woodland. Ecol. Monographs, 16: 49-86.

Greig-Smith, M. A. (1964) - Quantitative plant ecology. Washington, Butterworths. $256 \mathrm{pp}$.

Mitchell, R. W. (1968) - Food and feeding habits in the troglobitic carabid beetle Rhadine subterranea. Int. J. Speleology, 4.

Reddell, J. R. (1963) - The caves of Williamson County. Texas Speleological Survey, 1 (2).

RICKER, W. E. (1948) - The concept of confidence or fiducial limits applied to the Poisson frequency distribution. J. Amer. Statistical Assn., 32: 349-356.

SNedecor, G. W. (1956) - Statistical methods. Ames, Iowa, The Iowa State Univ. Press. 534 pp.

VAN DyKe, E. C. (1918) - A new genus and species of cave-dwelling Carabidae (Coleoptera) from the United States. J. New York Entomol. Soc., 26: 179-182. 






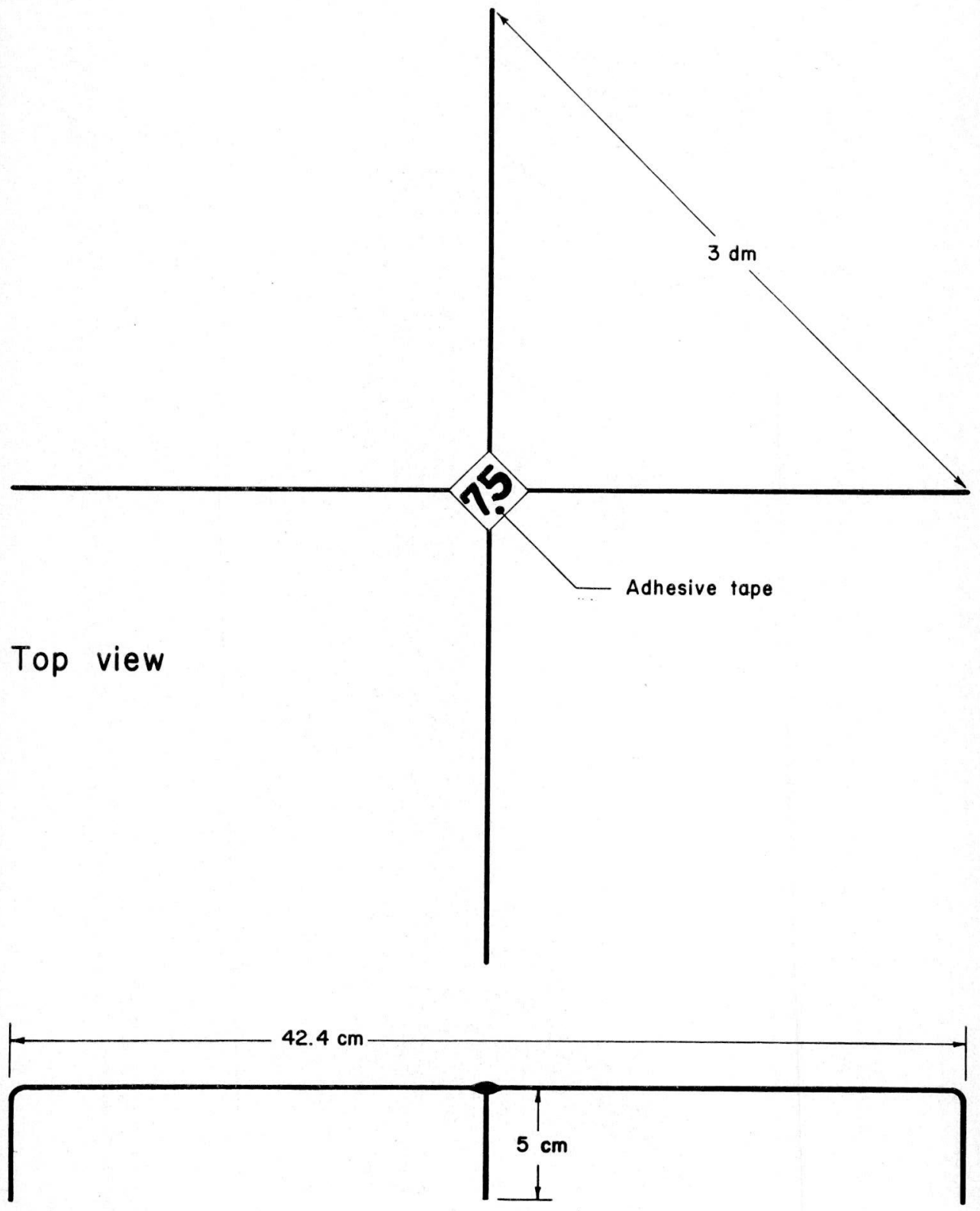

Side view 


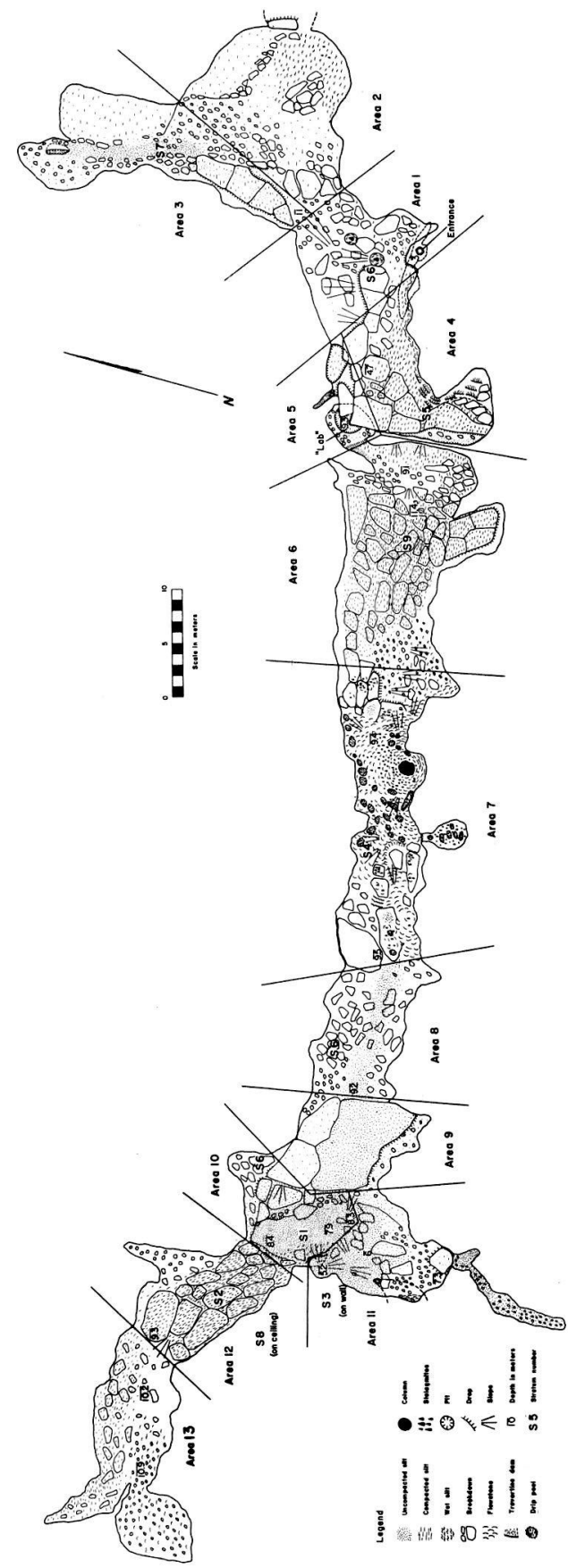

